\title{
Individual Burden of Psoriasis (I-BOP): Building and Validation of a New Scoring Tool for Patients with Psoriasis
}

This article was published in the following Dove Press journal:

Clinical, Cosmetic and Investigational Dermatology

\author{
Khaled Ezzedine' \\ Anne Claire Fougerousse (iD) ${ }^{2,3}$ \\ Roberte Aubert ${ }^{4}$ \\ Jean-Benoît Monfort (iD ${ }^{5}$ \\ Ziad Reguiaï ${ }^{3,6}$ \\ Jason Shourick ${ }^{7}$ \\ Charles Taieb $^{8,9, *}$ \\ François Maccari ${ }^{3,10, *}$ \\ 'EA EpiDermE UPEC Université Paris-Est \\ Créteil, Creteil, France; ${ }^{2}$ Hôpital d'in- \\ struction des armées, Saint-Mandé, \\ France; ${ }^{3}$ Resopso, Paris, France; ${ }^{4}$ France \\ Psoriasis, Association de Patients, Paris, \\ France; ${ }^{5}$ Hôpital Tenon, Paris, France; \\ ${ }^{6}$ Service de Dermatologie, Polyclinique \\ Courlancy-Bezannes, Reims, France; \\ ${ }^{7}$ Université Paris Sud, Paris, France; \\ ${ }^{8}$ Santé Publique, Hôpital Necker Enfants \\ Malades, Paris, France; ${ }^{9}$ European Market \\ Maintenance Assessment, Fontenay-sous- \\ Bois, France; ${ }^{10}$ Private Practice, La \\ Varenne Saint Hilaire, France \\ *These authors contributed equally to \\ this work
}

Background: Psoriasis impacts independently of its severity on patients' lifestyle and quality of life (QoL).

Aim: To build a tool for assessing the patient-reported psoriasis burden.

Methods: An expert group created a questionnaire using a standardized methodology building questionnaires assessing quality of life issues. The questionnaire was translated from French into a cultural and linguistically validated US English version.

Results: A conceptual questionnaire of 54 questions was created. The confirmatory analyses resulted in a 10 -feature questionnaire divided into 4 internally consistent domains with a Cronbach's alpha coefficient of 0.9 . It was reproducible and highly reliable. It correlated well with the Dermatology Life Quality Index (DLQI), Perceived Stress Scale (PSS), and SF-12 mental and SF12 physical scores.

Conclusion: This tool allows for the first time to assess the burden of psoriasis patients. Its use may allow improving medical and nonmedical patient care, thus improving their daily life.

Keywords: disease burden, psoriasis, quality of life, questionnaire, standardized method

\section{Introduction}

Psoriasis is a chronic condition requiring life-long treatment. Its worldwide prevalence has been estimated at approximately $1-3 \% .{ }^{1}$ It is mainly observed on the skin but may also affect joints. Up to $42 \%$ of patients with psoriasis also have associated psoriatic arthritis. ${ }^{2,3}$ Moreover, an increased risk of obesity, diabetes, and cardiovascular events has been reported for psoriasis patients. ${ }^{4,5}$

But, psoriasis may also cause a psychiatric burden. In psoriasis patients, the appearance and discomfort of lesions, especially if visible, negatively impact selfesteem and quality of life (QoL) and may cause depression. ${ }^{6-9}$ Patients with psoriasis are tempted to cover visible zones attempted, may suffer from sexual problems, and avoid physical activities and may feel ashamed, anxious, and frustrated. $^{6,10}$ As a result, treatment efficacy maybe impacted through a lack of compliance, starting a vicious circle. ${ }^{11}$ Therefore, identifying the most vulnerable patients may not only allow managing these psychological issues but also improve their adherence to treatment. ${ }^{12}$

"Global Disease Burden" was defined for the first time by the World Health Organization. ${ }^{13,14}$ Today, the focus of burden also applies to the individual disease
Correspondence: Charles Taieb

Tel +33771772100

Email charles.taieb@emma.clinic 
burden, comprising psychological, social, economic, and physical features. In psoriasis, infantile haemangioma, hereditary ichthyoses, atopic dermatitis, vitiligo, albinism and palmoplantar keratoderma, individual disease burden has already been evaluated. ${ }^{15-21}$

According to our literature search, no specific instrument exists to assess the burden experienced by psoriasis patients. However, such a tool may be useful for both patients and clinicians in charge of patient management. This instrument may, firstly, help to describe patient perceptions and, secondly, allow monitoring any changes in medical and non-medical care.

The aim of the present work was to build a self-administered tool allowing assessing the individual disease burden in psoriasis patients.

\section{Methodology}

Compiling this self-administered questionnaire did not require the approval of national health authorities. The work received approval from the national Ethics committee in July 2018. According to French regulations, no written informed consent was to be obtained from participating patients.

The tool was built following a standard methodology for creating QoL questionnaires. ${ }^{22}$ A group of experts in the design and development of questionnaires, such as health-care professionals (physicians and public-health specialists) as well as medical experts in psoriasis were created to validate the questionnaire.

A question and answer format was used. The response format followed a 7-point Likert scale: "never" (0), "rarely" (1), "sometimes" (2), "often" (3), "very often" (4), "constantly" (5) "not concerned" (0). The majority of all questions included the wording "due to my psoriasis". This was to avoid any confusion with changes in perception due to symptoms related to comorbidities.

\section{Conception}

Prior to building the questionnaire, the authors conducted a literature research on PubMed to identify published work about questionnaires or scoring systems related to psoriasis. The authors performed several interviews with dermatologists, patient-reported outcome (PRO) experts, and psoriasis patients to collect the perception and complaints of patients as well as data for the initial wording. Based on the wording reports a list of features was prepared. These features were reformulated as easy-to-understandable questions.
Interviews ensured a large recruitment and a coherent diversity of participants regarding their geographical location, age, and sociological status; questionnaires were used to clinically confirm psoriasis. The working group semantically analysed the initial phrasing and finalised the list of questions. If similarities were too strong then questions were combined.

As a result, a semi-structured "Individual Burden of Psoriasis (I-BOP)" questionnaire using closed-ended questions was built. This tool covered relationships with others, economic consequences, impact on work, impact on daily life, on sexuality and libido.

\section{Development}

The conceptual questionnaire was administered to a random sample of psoriasis patients selected at the author's practice facilities. Questionnaires were analysed using an exploratory factor analysis to reveal latent constructs. Each feature was assigned to its respective domain or dimension.

Questions with a too low or too high inter-feature correlation (lower than 0.3 or higher than 0.9 ) were eliminated. A Keyser Meyer Odin (KMO) analysis was conducted ensuring an appropriate factor analysis (KMO over 0.4 for all features).

Moreover, an exploratory factor analysis was done using a promax rotation to determine the domain or dimension of each feature. ${ }^{23}$ Features with a low factor loading (lower than 0.4 ) or a high cross factor loading (higher than 0.2) were excluded.

\section{Validation}

\section{Internal validation}

Features were tested for their the homogeneity in each dimension using the Cronbach's alpha coefficient. ${ }^{24}$ Higher scores $(>0.7)$ suggest good homogeneity.

A confirmatory analysis for the higher-order factor was done in order to demonstrate the questionnaire's unidimensionality. The model's suitability was measured using several criteria, including the Bentler comparative fit index and the Bentler-Bonett non-normed fit index both were set at $>0.90 .^{25}$ The root mean square error of approximation (RMSEA) was set at 0.05 or at the very least $<0.08$, with 0.05 being the confidence interval.

\section{External Validation}

All participants were asked to complete the 12-feature Short Form Health Survey (SF12), Dermatology Life 
Quality Index (DLQI) questionnaire and Perceived Stress Scale (PSS). ${ }^{26-28}$ The SF12 is a short version of the SF$36 .^{29}$ Based on 12 questions, a physical composite score (PCS, SF-12P) and mental composite score (MCS, SF$12 \mathrm{M})$ were calculated. The DLQI questionnaire assesses the impact of skin diseases and associated treatments on patient QoL in patients aged above 16 years. The PSS measures the perception of stress.

A Pearson correlation was calculated assessing the reliability between the I-BOP questionnaire and these 3 questionnaires.

All data were analysed using R software version 3.5.3 for Windows, with a significance level set at 0.05 .

\section{Test-Retest Validation}

Test-retest analyses assess reproducibility. Participants completed the I-BOP questionnaire twice within a 2week interval. Answers were compared and the reliability of measurements was confirmed.

\section{Translation, Cross-Cultural Adaptation, and Cognitive Debriefing}

A US English-language version according to the recommendations of the ISPOR task force was issued. ${ }^{30}$ The different conception, development, and validation steps are summarized in (Table 1).

\section{Results}

\section{Conception}

The literature review identified 11 psoriasis-related questionnaires and scoring systems. ${ }^{31-41}$ Verbal exchanges and several face-to-face meetings took place between dermatologists, psychologists, social workers, and patientreported outcome (PRO) experts. In addition, the perception and complaints regarding psoriasis of 20 participants served for the conception of the tool. As a result, an initial verbatim, leading to a 54-feature conceptual questionnaire was created. Questions were categorized into relationships with others, economic consequences, impact on work and impact on everyday life and formatted using the 7-answer Likert scale.

\section{Development}

In total, 377 patients who attended the author's clinics and patients of the Reso-Pso network were invited to test the conceptual questionnaire. Patients with psoriatic arthritis were not considered for statistical analyses. Thus, 208 patients were suitable for testing the tool.
Table I Principles of Good Practice for the Translation and Cultural Adaptation Process for Patient-Reported Outcomes (PRO) Measures

\begin{tabular}{|l|l|}
\hline Stage & Details \\
\hline Preparation & $\begin{array}{l}\text { Evaluation of the source text from } \\
\text { a linguistic and cultural point of } \\
\text { view including definition of } \\
\text { concepts }\end{array}$ \\
\hline Forward translations & $\begin{array}{l}\text { Forward translation into the } \\
\text { required target language by two } \\
\text { independent translators }\end{array}$ \\
\hline Reconciliation & $\begin{array}{l}\text { Comparison of the two forward } \\
\text { translations to provide the best } \\
\text { adapted and to produce a draft } \\
\text { version of the text }\end{array}$ \\
\hline Back translation & $\begin{array}{l}\text { Translation of the draft forward } \\
\text { translation back into the targeted } \\
\text { language without reference to the } \\
\text { original language }\end{array}$ \\
\hline Analysis and implementation of \\
back translation review report
\end{tabular}

Note: Data from Wild et al. ${ }^{30}$

Once all questionnaires were collected and evaluated, the working group performed a semantic analysis of the initial conceptual questionnaire. Non-discriminating questions (questions for which more than $90 \%$ of the responders, regardless of sex or age, provided identical answers) and questions for which wording was considered non-pertinent were eliminated, resulting in an 18 -feature questionnaire.

Following this selection, an inter-feature correlation matrix was created in order to compile a condensed questionnaire. Results from this matrix correlation eliminated 4 more questions which all presented with an inter-feature correlation factor of less than 0.3 or of more than 0.9 , resulting in a 14-feature questionnaire. 


\section{Exploratory Factor Analysis}

All KMO scores confirmed that the dataset is suitable for conducting an EFA (exploratory factor analysis).

The scree plot obtained through the EFA determined 2 pertinent dimensions (Figure 1).

Moreover, this analysis eliminated questions with a loading factor of less than 0.5 or with a cross factor of more than 0.25 (Table 2). As a result, 4 more questions were eliminated from the questionnaire, leading to a 10feature questionnaire. The semantic analysis identified 2 domains: "personal perception", covering 6 questions and "perception of others" covering 4 questions (Figure 2).

\section{Validation}

The resulting 10-feature questionnaire was distributed together with SF-12, DLQI and PSS questionnaires to 623 patients attending the authors' facilities and members of the Reso-Pso network; answers from patients with psoriatic arthritis were not considered. Thus, 550 psoriasis patients participated in this internal validation.

\section{Internal Validation}

The higher-order factor analysis resulted in a practical suitability index of 0.845404 , with a Bentler comparative fit index (CFI) of 0.0.8644876, Bentler-Bonett non-normed fit index of 0.8549433 , and an RMSEA index of 0.1444259
(95\% CI [0.1323132; 0.1568747]). Based on these indicators and according to Kenny and McCoach, the model was proven to be correctly adjusted and suitable; the 2 dimensions could be grouped together into one single overall score. ${ }^{42}$

The Cronbach's alpha coefficient was 0.9 for the entire questionnaire, confirming its excellent internal coherence.

\section{External Validation}

The questionnaire highly correlated with the SF-12 (SF12P: -0.12 and SF-12M: -0.49$)$, DLQI (0.77) and PSS (0.47) questionnaires.

\section{Test-Retest Analysis}

The test-retest reliability was made by 58 participants at Day 0 and Day 10; 47 usable test results were obtained; for 11 participants only the questionnaire for Day 0 was collected. Reproducibility was very good; the intra-class correlation of each dimension exceeded $85 \%$ for each domain, the total intra-class correlation (ICC) score was 0.98 with a CI $95 \%$ of $[0.952,0.991]$. A first scale ICC reached 0.986 with a CI $95 \%$ of $[0.969,0.994]$ and the second scale ICC was 0.959 with a CI $95 \%$ of $[0.91,0.984]$.

\section{Cognitive Debriefing, Translation, and Cross-Cultural Adaptation}

Cognitive debriefing required no changes of the wording. The original French version was translated and underwent

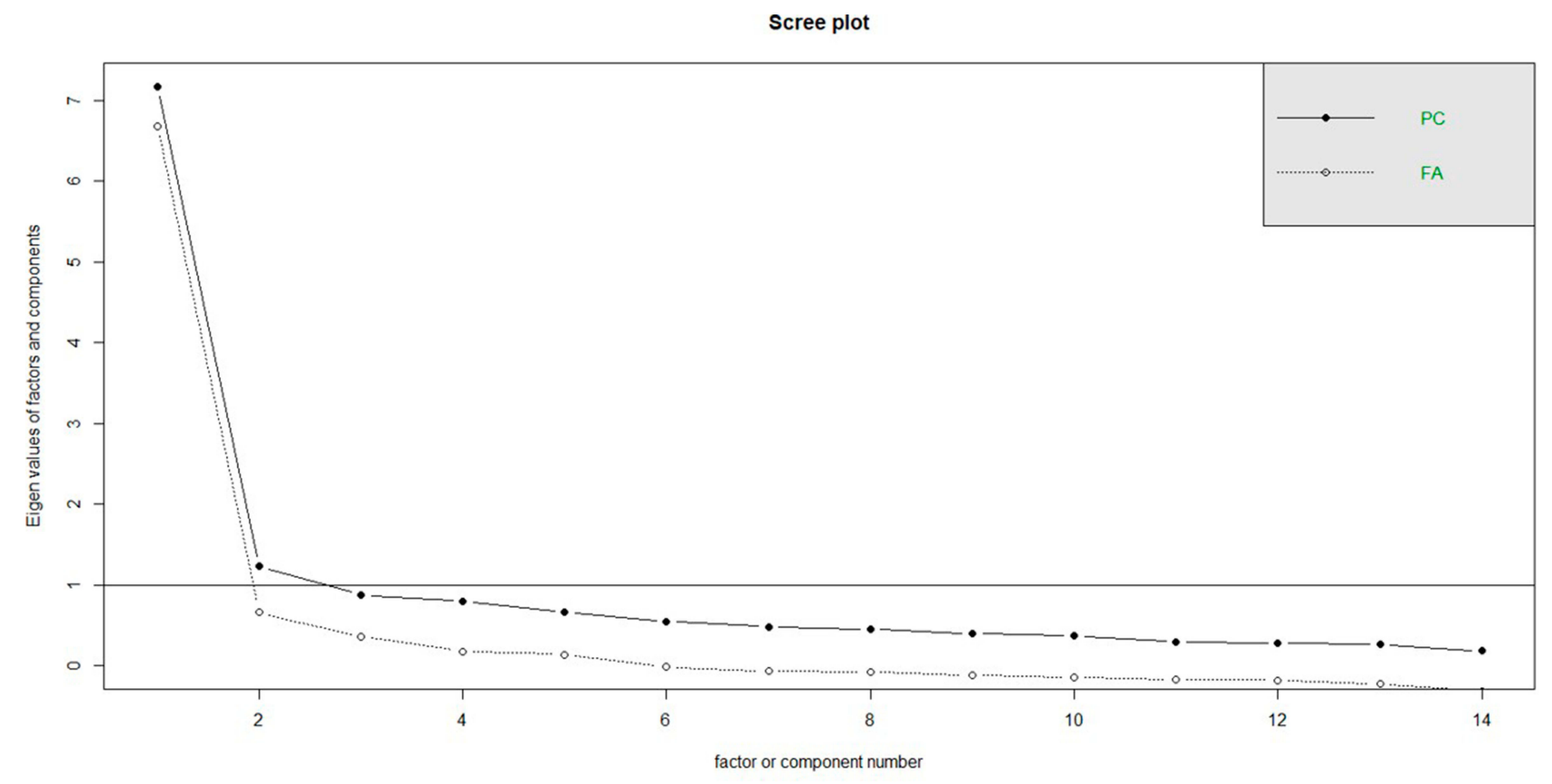

Figure I Exploratory factor analysis: scree plot. The scree plot served to determine the number of dimensions. Abbreviations: FA, factor analysis; PC, principal component. 
Table 2 Exploratory Factor Analysis: Questions with a Loading Factor of Less Than 0.5 or with a Cross Factor of More Than 0.25

\begin{tabular}{|l|l|l|}
\hline & MRI & MR2 \\
\hline Question I & 0.38 & 0.27 \\
Question 2 & 0.85 & -0.03 \\
Question 3 & -0.15 & 0.77 \\
Question 4 & -0.13 & 0.87 \\
Question 5 & 0.82 & -0.19 \\
Question 6 & 0.64 & 0.06 \\
Question 7 & 0.73 & 0.05 \\
Question 8 & 0.19 & 0.42 \\
Question 9 & 0.08 & 0.59 \\
Question 10 & 0.06 & 0.64 \\
Question II & 0.50 & 0.33 \\
Question 12 & 0.55 & 0.29 \\
Question 13 & 0.44 & 0.40 \\
Question 14 & 0.92 & -0.06 \\
\hline
\end{tabular}

Abbreviation: MR, minimum rank.

linguistic and cultural validation into US English. The final, validated version is given in (Table 3 ).

\section{Scoring}

Summing up scores for each of the 10 questions allowed calculating the total tool score. This was defined in the aforementioned method description, with "never" or "not applicable" scoring 0, "rarely" 1, "sometimes" 2, "often" 3 , "very often" 4, and "constantly" 5 and with an I-BOP total score of " 0 " = no impact to " $70 "=$ highest possible impact.

\section{Discussion and Conclusion}

Psoriasis impacts independently of its severity on the patient's lifestyle and QoL. ${ }^{43}$ To the best of our knowledge, to date, no tool exists assessing the overall burden of psoriasis patients. Here we provide an easy-to-use tool allowing assessing the individual psoriasis burden. It is currently available in French and US English.

This newly developed burden assessment tool is robust with an internal consistency exceeding the minimum reliability criterion of 0.90 for an individual analysis.

The issue of individual disease burden is increasingly investigated especially for chronic skin diseases known for psychosocially affecting the patient. It is well established that "Individual burden" is responsible for disability caused by diseases. It covers psychological, physical, social, and economic factors, impacting QoL, social interaction, everyday life, and medical care. Using questionnaires allows evaluating this burden. ${ }^{15-17,19,22}$

Advances made in QoL research over the last decades allowed health-care givers and regulatory agencies facing

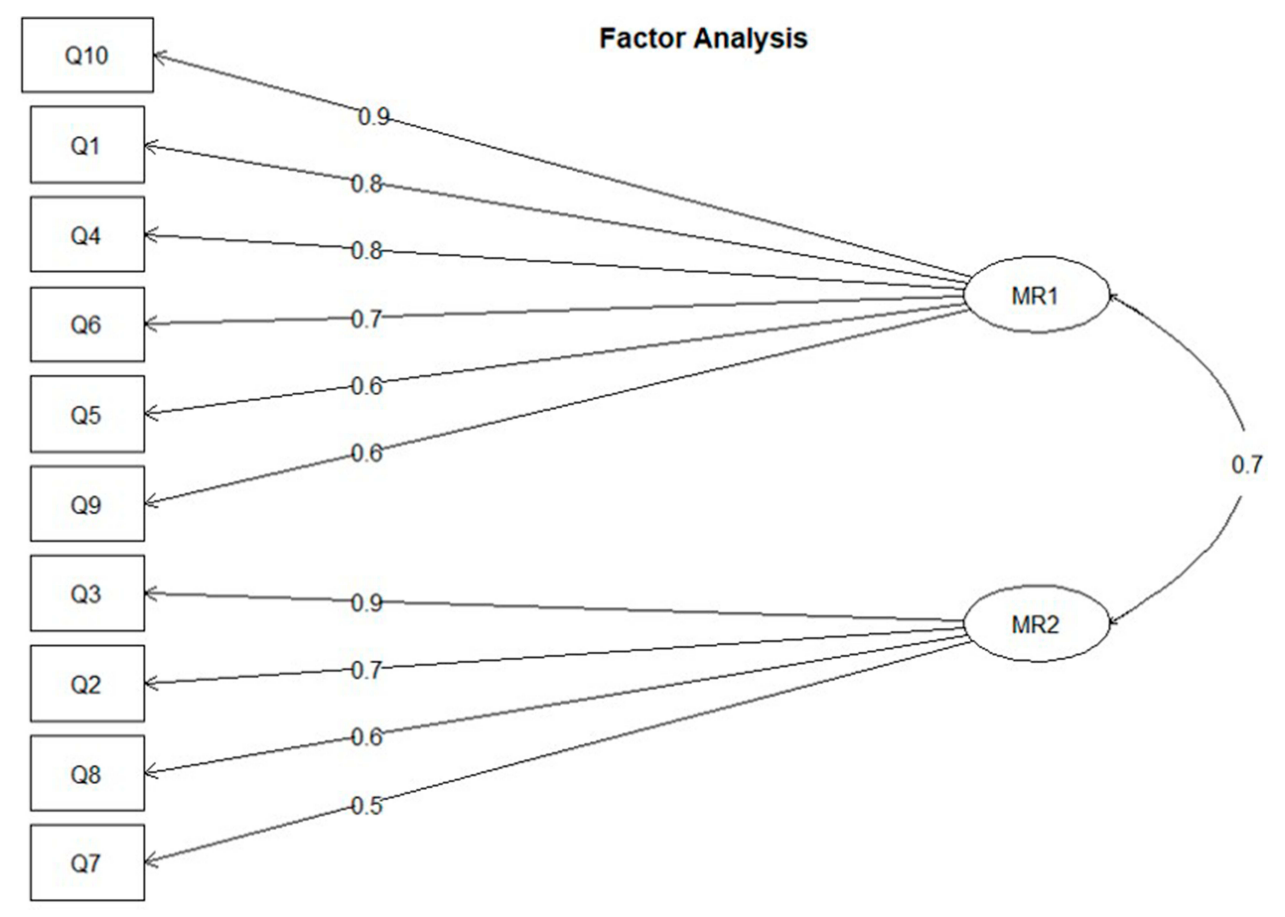

Figure 2 Exploratory factor analysis: Semantic analysis. The exploratory factor analysis allowed determining of domains: Domain I (MRI): own perception and Domain 2 (MR2): perception of others. 
Table 3 10-Feature I-BOP Questionnaire

\begin{tabular}{|l|l|l|l|l|l|l|l|}
\hline & Always & $\begin{array}{l}\text { Very } \\
\text { Often }\end{array}$ & Often & Sometimes & Rarely & $\begin{array}{l}\text { Never } \\
\text { Not } \\
\text { Applicable }\end{array}$ \\
\hline Have you felt that your psoriasis is an aesthetic burden? & $\square$ & $\square$ & $\square$ & $\square$ & $\square$ & $\square$ & $\square$ \\
\hline Do you worry about your psoriasis flaring up? & $\square$ & $\square$ & $\square$ & $\square$ & $\square$ & $\square$ & $\square$ \\
\hline Have you worried that the marks or scars will be permanent? & $\square$ & $\square$ & $\square$ & $\square$ & $\square$ & $\square$ & $\square$ \\
\hline Has your psoriasis made you angry? & $\square$ & $\square$ & $\square$ & $\square$ & $\square$ & $\square$ & $\square$ \\
\hline Have you felt discouraged because of your psoriasis? & $\square$ & $\square$ & $\square$ & $\square$ & $\square$ & $\square$ & $\square$ \\
\hline $\begin{array}{l}\text { Have you been unhappy with your appearance because of your } \\
\text { psoriasis? }\end{array}$ & $\square$ & $\square$ & $\square$ & $\square$ & $\square$ & $\square$ & $\square$ \\
\hline In your opinion, has your psoriasis had an impact on your sex life? & $\square$ & $\square$ & $\square$ & $\square$ & $\square$ & $\square$ & $\square$ \\
\hline Have you felt tired because of your psoriasis? & $\square$ & $\square$ & $\square$ & $\square$ & $\square$ & $\square$ & $\square$ \\
\hline Have you found it hard to work because of your psoriasis? & $\square$ & $\square$ & $\square$ & $\square$ & $\square$ & $\square$ & $\square$ \\
\hline Have you found it difficult to concentrate because of your psoriasis? & $\square$ & $\square$ & $\square$ & $\square$ & $\square$ & $\square$ & $\square$ \\
\hline
\end{tabular}

multifaceted situations. ${ }^{16}$ In this context, Cohen et al prepared recommendations for basing all health-related QoL claims on rigorously designed studies. ${ }^{27}$ The use of QOL questionnaires in clinical research is more and more frequent to achieve market access. ${ }^{19}$

In conclusion, the I-BOP questionnaire is a reliable tool. It may help to better appreciate the multidimensional nature of psoriasis. Moreover, it may help to better understand the individual burden of psoriasis patients and as such may play a key role in the decision-making process. Additional research to develop a version of the instrument for children in the near future is ongoing.

\section{Acknowledgments}

The authors acknowledge the support of the French Association of Psoriasis Patients Réso Pso, the participating patients and physicians, and the writing assistance of Karl Patrick Göritz, SMWS Scientific and Medical Writing Services.

\section{Funding}

This study was funded by Laboratoire Pharmaceutique Lilly France.

\section{Disclosure}

Dr Anne Claire Fougerousse is advisory board for Abbvie, Eli-Lilly, Janssen Cilag, and Novartis; speaker for from Celgene and UCB. Dr Ziad Reguiai reports grants, personal fees from Lilly, Abbvie, Celgene, Janssen-Cilag,
Novartis, Leo Pharma, UCB, Pfizer. Dr Francois Maccari reports grants from Janssen, Novartis, Abbvie, and Lilly. The authors report no other conflicts of interest in this work.

\section{References}

1. Myers WA, Gottlieb AB, Mease P. Psoriasis and psoriatic arthritis: clinical features and disease mechanisms. Clin Dermatol. 2006;24 (5):438-447. doi:10.1016/j.clindermatol.2006.07.006

2. Green L, Meyers OL, Gordon W, Briggs B. Arthritis in psoriasis. Ann Rheum Dis. 1981;40(4):366-369. doi:10.1136/ard.40.4.366

3. Eder L, Haddad A, Rosen CF, et al. The incidence and risk factors for psoriatic arthritis in patients with psoriasis: a prospective cohort study. Arthritis Rheumatol. 2016;68(4):915-923. doi:10.1002/art.39494

4. Reich K. The concept of psoriasis as a systemic inflammation: implications for disease management. $J$ Eur Acad Dermatol Venereol. 2012;26(Suppl 2):3-11. doi:10.1111/j.1468-3083.2011.04410.x

5. Gelfand JM, Neimann AL, Shin DB, Wang X, Margolis DJ, Troxel AB. Risk of myocardial infarction in patients with psoriasis. JAMA. 2006;296(14):1735-1741. doi:10.1001/jama.296.14.1735

6. Khoury LR, Danielsen PL, Skiveren J. Body image altered by psoriasis. A study based on individual interviews and a model for body image. $J$ Dermatol Treat. 2014;25(1):2-7. doi:34.2012.739278",1,0,0>10.3109/095466

34.2012 .739278

7. Mease PJ, Menter MA. Quality-of-life issues in psoriasis and psoriatic arthritis: outcome measures and therapies from a dermatological perspective. J Am Acad Dermatol. 2006;54(4):685-704. doi:10.1016/j. jaad.2005.10.008

8. Dommasch ED, Li T, Okereke OI, Li Y, Qureshi AA, Cho E. Risk of depression in women with psoriasis: a cohort study. $\mathrm{Br} J$ Dermatol. 2015;173(4):975-980. doi:10.1111/bjd.14032

9. Dowlatshahi EA, Wakkee M, Arends LR, Nijsten T. The prevalence and odds of depressive symptoms and clinical depression in psoriasis patients: a systematic review and meta-analysis. J Invest Dermatol. 2014;134(6):1542-1551. doi:10.1038/jid.2013.508 
10. Sampogna F, Tabolli S, Abeni D. Living with psoriasis: prevalence of shame, anger, worry, and problems in daily activities and social life. Acta Derm Venereol. 2012;92(3):299-303. doi:10.2340/00015555-1273

11. Fortune DG, Richards HL, Kirby B, et al. Psychological distress impairs clearance of psoriasis in patients treated with photochemotherapy. Arch Dermatol. 2003;139(6):752-756. doi:10.1001/ archderm.139.6.752

12. Nicholas MN, Gooderham M. Psoriasis, depression, and suicidality. Skin Therapy Lett. 2017;22(3):1-4.

13. Dalgard FJ, Gieler U, Tomas-Aragones L, et al. The psychological burden of skin diseases: a cross-sectional multicenter study among dermatological out-patients in 13 European countries. $J$ Invest Dermatol. 2015;135(4):984-991. doi:10.1038/jid.2014.530

14. WHO. About the global burden of disease (GBD) project 2010. [cited April 05, 2019]. Available from: https://www.who.int/ healthinfo/global_burden_disease/about/en/. Accessed September 05, 2019.

15. Meyer N, Paul C, Feneron D, et al. Psoriasis: an epidemiological evaluation of disease burden in 590 patients. J Eur Acad Dermatol Venereol. 2010;24(9):1075-1082. doi:10.1111/j.1468-3083.2010.03600.x

16. Boccara O, Meni C, Leaute-Labreze C, et al. Haemangioma family burden: creation of a specific questionnaire. Acta Derm Venereol. 2015;95(1):78-82. doi:10.2340/00015555-1847

17. Dufresne H, Hadj-Rabia S, Méni C, Sibaud V, Bodemer C, Taïeb C. Family burden in inherited ichthyosis: creation of a specific questionnaire. Orphanet J Rare Dis. 2013;8:28. doi:10.1186/1750-1172-828

18. Taieb A, Boralevi F, Seneschal J, et al. Atopic dermatitis burden scale for adults: development and validation of a new assessment tool. Acta Derm Venereol. 2015;95(6):700-705. doi:10.2340/00015555-1945

19. Salzes C, Abadie S, Seneschal J, et al. The vitiligo impact patient scale (VIPs): development and validation of a vitiligo burden assessment tool. J Invest Dermatol. 2016;136(1):52-58. doi:10.1038/ JID.2015.398

20. Morice-Picard F, Taieb C, Marti A, et al. Burden of albinism: development and validation of a burden assessment tool. Orphanet J Rare Dis. 2018;13(1):162. doi:10.1186/s13023-018-0894-3

21. Hickman G, Bodemer C, Bourrat E, Bennani M, Taieb C. Palmoplantar keratoderma: creating a disease burden questionnaire. J Eur Acad Dermatol Venereol. 2019;33(8):e291-e293. doi:10.1111/ jdv. 15563

22. Seidenberg M, Haltiner A, Taylor MA, Hermann BB, Wyler A. Development and validation of a multiple ability self-report questionnaire. J Clin Exp Neuropsychol. 1994;16(1):93-104. doi:10.1080/ 01688639408402620

23. Kaiser HF. The varimax criterion for analytic rotation in factor analysis. Psychometrika. 1958;23(3):187-200. doi:10.1007/BF02289233

24. Cronbach LJ. Coefficient alpha and the internal structure of tests. Psychometrika. 1951;16(3):297-334. doi:10.1007/BF02310555

25. Bentler PM. Comparative fit indexes in structural models. Psychol Bull. 1990;107(2):238-246. doi:10.1037/0033-2909.107.2.238

26. Lim LL, Fisher JD. Use of the 12-item short-form (SF-12) health survey in an Australian heart and stroke population. Qual Life Res. 1999;8(12):1-8. doi:10.1023/A:1026409226544

27. Cohen S, Kamarck T, Mermelstein R. A global measure of perceived stress. J Health Soc Behav. 1983;24(4):385-396. doi:10.2307/2136404

28. Finlay AY, Khan GK. Dermatology life quality index (DLQI)-a simple practical measure for routine clinical use. Clin Exp Dermatol. 1994;19 (3):210-216. doi:10.1111/j.1365-2230.1994.tb01167.x
29. Brazier JE, Harper R, Jones NM, et al. Validating the SF-36 health survey questionnaire: new outcome measure for primary care. $B M J$. 1992;305(6846):160-164. doi:10.1136/bmj.305.6846.160

30. Wild D, Grove A, Martin M, et al. Principles of good practice for the translation and cultural adaptation process for patient-reported outcomes (PRO) measures: report of the ISPOR task force for translation and cultural adaptation. Value Health. 2005;8(2):94-104. doi:10.1111/j.1524-4733.2005.04054.x

31. Ramsay B, Lawrence CM. Measurement of involved surface area in patients with psoriasis. $B r J$ Dermatol. 1991;124(6):565-570. doi:10.1111/j.1365-2133.1991.tb04952.x

32. Langley RG, Feldman SR, Nyirady J, van de Kerkhof P, Papavassilis C. The 5-point investigator's global assessment (IGA) scale: a modified tool for evaluating plaque psoriasis severity in clinical trials. J Dermatol Treat. 2015;26(1):23-31. doi:10.3109/09546634.2013.865009

33. Fredriksson T, Pettersson U. Severe psoriasis-oral therapy with a new retinoid. Dermatologica. 1978;157(4):238-244. doi:10.1159/ 000250839

34. Finlay AY. Quality of life assessments in dermatology. Semin Cutan Med Surg. 1998;17(4):291-296. doi:10.1016/S1085-5629(98)800266

35. Gupta MA, Gupta AK. Psychiatric and psychological co-morbidity in patients with dermatologic disorders: epidemiology and management. Am J Clin Dermatol. 2003;4(12):833-842. doi:10.2165/00128071200304120-00003

36. Bhushan M, Burden AD, McElhone K, James R, Vanhoutte FP, Griffiths CE. Oral liarozole in the treatment of palmoplantar pustular psoriasis: a randomized, double-blind, placebo-controlled study. $\mathrm{Br} \mathrm{J}$ Dermatol. 2001;145(4):546-553. doi:10.1046/j.13652133.2001.04411.x

37. Koo J, Menter A, Lebwohl M, et al. The relationship between quality of life and disease severity: results from a large cohort of mild, moderate and severe psoriasis patients. $\mathrm{Br} J$ Dermatol. 2002;147:1077-1079.

38. McKenna SP, Doward LC, Whalley D, Tennant A, Emery P, Veale DJ. Development of the PsAQoL: a quality of life instrument specific to psoriatic arthritis. Ann Rheum Dis. 2004;63(2):162-169. doi:10.1136/ard.2003.006296

39. Bushnell DM, Martin ML, McCarrier K, et al. Validation of the psoriasis symptom inventory (PSI), a patient-reported outcome measure to assess psoriasis symptom severity. J Dermatol Treat. 2013;24 (5):356-360. doi:10.3109/09546634.2012.742950

40. Mathias SD, Feldman SR, Crosby RD, Colwell HH, McQuarrie K, Han C. Measurement properties of a patient-reported outcome measure assessing psoriasis severity: the psoriasis symptoms and signs diary. J Dermatol Treat. 2016;27(4):322-327. doi:10.3109/ 09546634.2015.1114567

41. Gilet H, Roborel de Climens A, Arnould B, et al. Development and psychometric validation of the reflective evaluation of psoriasis efficacy of treatment and severity (REFLETS) questionnaire: a common measure of plaque-type psoriasis severity and treatment efficacy for patients and clinicians. J Eur Acad Dermatol Venereol. 2015;29 (3):498-506. doi:10.1111/jdv.12601

42. Kenny DA, McCoach DB. Effect of the number of variables on measures of fit in structural equation modeling. Struct Equ Modeling. 2003;10(3):333-351. doi:10.1207/S15328007SEM1003_1

43. Garcia-Sanchez L, Montiel-Jarquin AJ, Vazquez-Cruz E, MaySalazar A, Gutierrez-Gabriel I, Loria-Castellanoso J. [Quality of life in patients with psoriasis]. Gac Med Mex. 2017;153(2):185-189. Spanish 


\section{Publish your work in this journal}

Clinical, Cosmetic and Investigational Dermatology is an international, peer-reviewed, open access, online journal that focuses on the latest clinical and experimental research in all aspects of skin disease and cosmetic interventions. This journal is indexed on CAS.
The manuscript management system is completely online and includes a very quick and fair peer-review system, which is all easy to use. Visit http://www.dovepress.com/testimonials.php to read real quotes from published authors. 